\title{
A 69-year-old male patient presenting with chest pain and shortness of breath
}

\author{
Y. Saleh $(D)$ K. Herzallah - M. Elsayed · S. Elkinany · S. Rayamajhi
}

Published online: 12 March 2019

(C) The Author(s) 2019

A 69-year-old male patient with a past medical history significant for aortic valve replacement via mechanical valve 35 years ago presented with acute shortness of breath and chest pain.

Upon examination, vital signs were significant for hypotension and tachycardia, lung and heart sounds were unremarkable. Laboratory investigations showed an international normalisation rate (INR) of 3 in addition to mildly elevated D-dimer, B-type natriuretic peptide (BNP) and troponin levels. Electrocardiography showed mild ST depression in the lateral leads, chest X-ray was unremarkable, myocardial perfusion imaging was negative for ischaemia and showed a preserved systolic function. Transthoracic echocardiography and computed tomography were performed (Fig. 1 and Video 1). What is causing his symptoms?

Electronic supplementary material The online version of this article (https://doi.org/10.1007/s12471-019-1259-9) contains supplementary material, which is available to authorized users.

Y. Saleh $(\bowtie) \cdot$ K. Herzallah $\cdot$ M. Elsayed $\cdot$ S. Elkinany $\cdot$

S. Rayamajhi

Michigan State University Clinical Center, East

Lansing, MI, USA

Yehia.saleh@hc.msu.edu

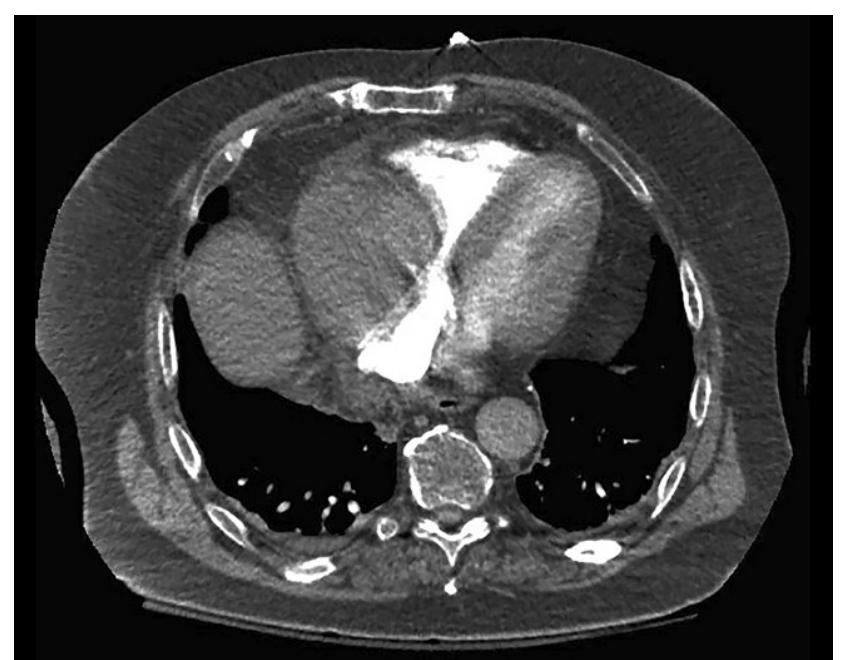

Fig. 1 The computed tomography image at presentation

\section{Answer}

You will find the answer elsewhere in this issue.

Open Access This article is distributed under the terms of the Creative Commons Attribution 4.0 International License (http://creativecommons.org/licenses/by/4.0/), which permits unrestricted use, distribution, and reproduction in any medium, provided you give appropriate credit to the original author(s) and the source, provide a link to the Creative Commons license, and indicate if changes were made. 